\title{
Decreased Aflatoxin Biosynthesis Upon Uptake of 20nm-sized Citrate Coated Silver Nanoparticles by the Aflatoxin producer Aspergillus parasiticus
}

\author{
Chandrani Mitra ${ }^{1}$, Soumitra Ghoshroy ${ }^{2}$, Jamie Lead ${ }^{1}$ and Anindya Chanda ${ }^{1}$ \\ 1. Environmental Health Sciences, University of South Carolina, Columbia, SC USA \\ 2. Electron Microscopy Center, University of South Carolina, Columbia, SC USA
}

The manufacture and usage of silver nanoparticles have drastically increased in recent years [1]. Hence, the feasibility of addition of high amounts of these nanoparticles into the environment through different routes has increased and is therefore a concern to environmental and public health [2]. Previous studies show that silver nanoparticles are toxic to various organisms: examples include toxicity against bacterial cells [3], aquatic plant cells [4], arthropods [5] and mammalian cells [6]. Recently toxicity of silver nanoparticles has also been demonstrated in fungal cells [7].

In this study we examined the effect of $20 \mathrm{~nm}$ sized citrate coated silver nanoparticles (cit-AgNp), synthesized and characterized (Fig. A) using previously established protocols [8], on growth and aflatoxin $\mathrm{B}_{1}$ biosynthesis in the filamentous fungus, Aspergillus parasiticus. Aflatoxin $\mathrm{B}_{1}$ is a mycotoxin and the most potent liver carcinogen known, associated with an estimated 25,200 and 155,000 liver cancer cases globally (Liu and $\mathrm{Wu} 2010$ ), and hence its contamination in food and feed is a significant risk factor of liver cancer in humans and animals (CAST 2003 ; Liu and Wu 2010). Aflatoxin producers, A. parasiticus and A. flavus are therefore the most characterized fungal models for studying mycotoxin biosynthesis. The 20nm AgNps are model silver nanoparticles that have been used consistently for toxicity assays in several models [9]. In a previous fungal toxicity study, $0.05 \mathrm{mg} / \mathrm{L}$ concentrations of $25 \mathrm{~nm}$ AgNps have demonstrated effective inhibition of fungal growth [7]. Here we show that $A$. parasiticus cells successfully uptake cit-AgNp upon exposure at the concentration of $0.05 \mathrm{mg} / \mathrm{L}$. While time-course inductively coupled plasma optical emission spectrometry (ICP-OES) performed simultaneously on growth media and mycelia (Fig. B) convincingly demonstrated cit-AgNp uptake, the time course dry weight analysis of mycelia (Fig. C b) demonstrated no changes in growth rate, suggesting that at the applied concentration, uptake of cit-AgNp were not toxic to the fungal cells. Uptake of cit-AgNp however, resulted in a significant reduction of the aflatoxin $\mathrm{B}_{1}$ in growth medium (Fig $\mathrm{C}$ a) suggesting that although uptake of these particles do not result in gross changes of primary metabolism in this fungus, its metabolic machinery for aflatoxin biosynthesis (secondary metabolism) is inhibited significantly.

Scanning electron micrographs and transmission electron micrographs of control mycelia and cit-AgNp up-taking mycelia (Fig. c $i$; ii) suggest that cit-AgNp localize predominantly at the cellular surface (Fig. c $i$ (right side)) and associates with morphological fluctuations of the cell surface (Fig. c $i$ (cit-AgNp treated A. parasiticus cell)). Overall, our findings implicate that while popular mycotoxin producers are robust to withstand and uptake silver nanoparticles, morphological fluctuations at their cell-environment interface during particle uptake can result in inhibition of mycotoxin biosynthesis and export into the environment [10]. 
Reference:

[1] Fabrega, J. et al., Environment international (2011). 37(2), 517-531.

[2] Panyala, N. R., Peña-Méndez, E. M., and Havel, J. (2008). J Appl Biomed, 6(3), 117-129.

[3] Kim, J. S. et al. (2007). Nanomedicine: Nanotechnology, Biology and Medicine, 3(1), 95-101.

[4] He, D., Dorantes-Aranda, J. J., and Waite, T. D. (2012). Environmental science \& technology, 46(16), 8731-8738.

[5] Khan, F. R. et al. (2015). Environmental science \& technology, 49(7), 4389-4397

[6] AshaRani, P. V. et al. (2008). ACS nano, 3(2), 279-290.

[7] Panáček, A. et al. (2009). Biomaterials, 30(31), 6333-6340.

[8] Römer, I. et al. (2011). Journal of Chromatography A, 1218(27), 4226-4233

[9] Park, J. et al. (2011). Chemical Communications, 47(15), 4382-4384.

[10] The authors acknowledge funding from the Department of Environmental Health Sciences, University of South Carolina. Dr. Mohammed Baalousha, Dr. Alan Decho and Dr. John Ferry are thanked for their many useful discussions and contributions to this work.
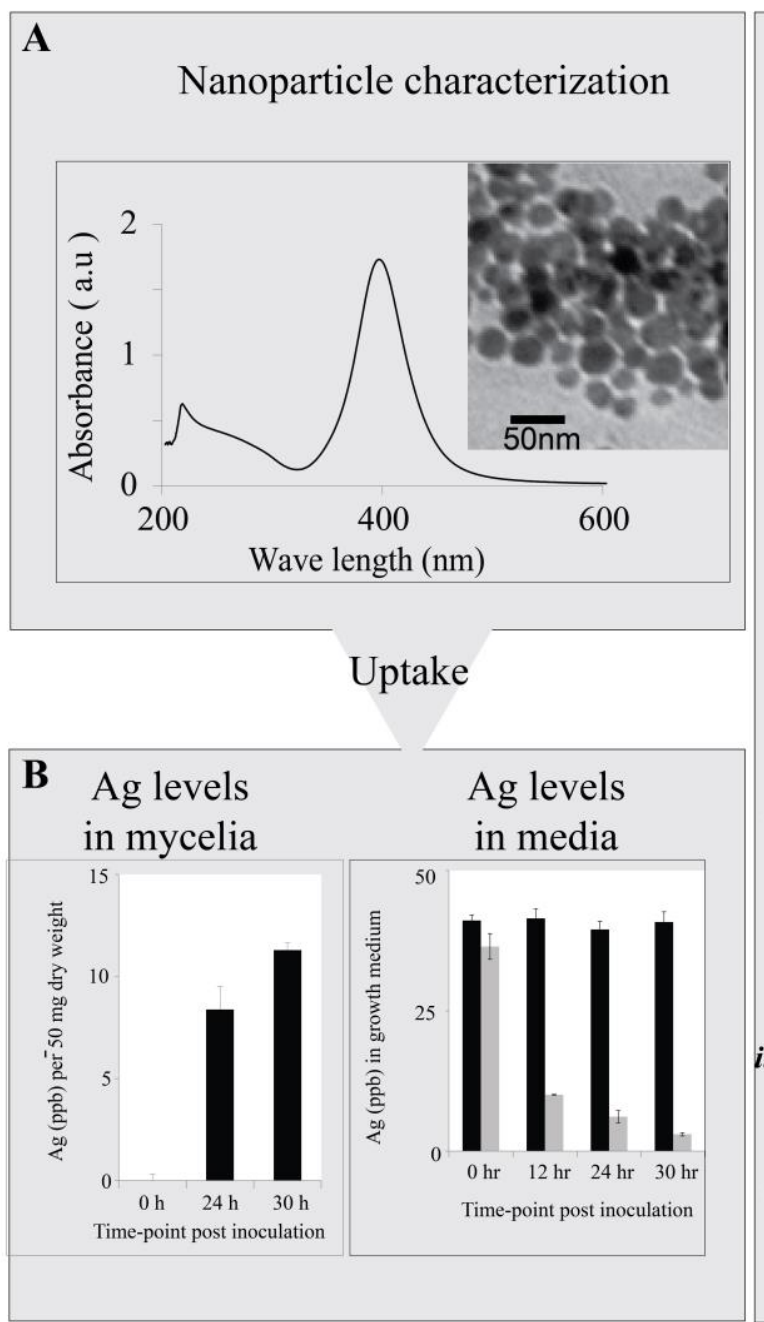
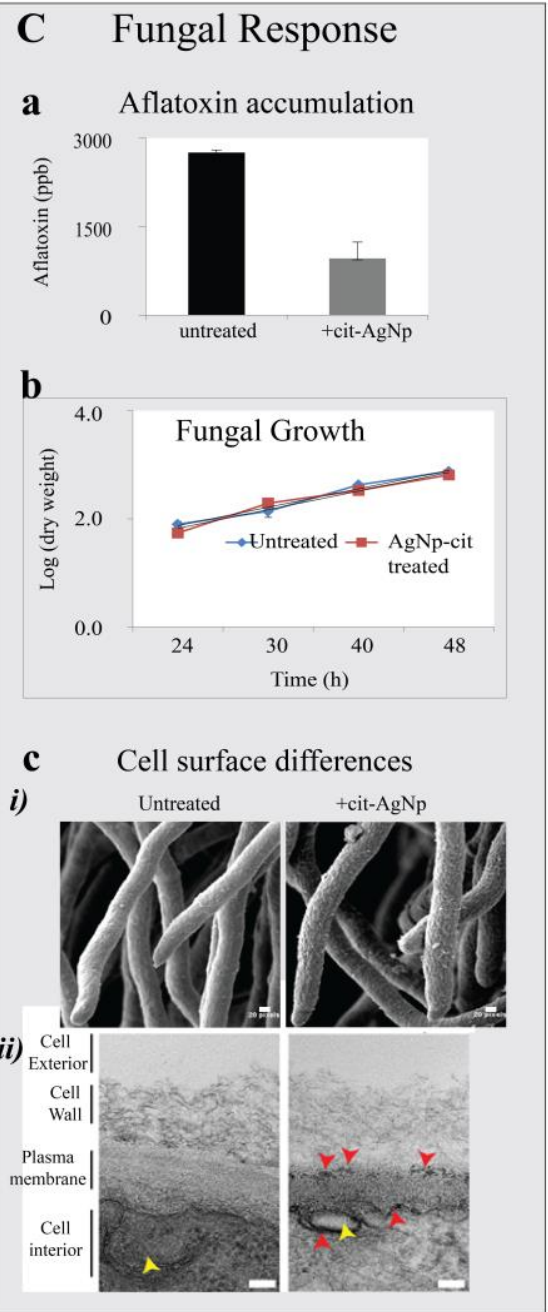

Figure 1. Uptake of citAgNp by Aspergillus parasiticus. A.

Characterization of citAgNp using UV-Vis plasmon resonance spectroscopy. B. ICPOES of mycelia (left panel) and growth medium (right panel) during uptake. Black bars in the right panel, Ag levels without the fungus. C. Effects of cit-AgNp uptake on (a) aflatoxin, (b) growth, and (c) cell surface using (i) Scanning electron microscopy and (ii) Transmission electron microscopy. Red arrow, cit-AgNp localization at the plasma membrane,

yellow arrows, endosomes originating from plasma membrane with cit- $\mathrm{AgNp}$ at the endosomal membrane. Scale Bars, c (i) $1 \mu \mathrm{m}$ (ii) $100 \mathrm{~nm}$. 